\title{
Fibroblast viability and phenotypic changes within glycated stiffened three-dimensional collagen matrices
}

Vanesa Vicens-Zygmunt ${ }^{1,2^{*}}$ (D), Susanna Estany ${ }^{2}$, Adai Colom³,8, Ana Montes-Worboys ${ }^{2}$, Carlos Machahua ${ }^{2}$, Andrea Juliana Sanabria ${ }^{4}$, Roger Llatjos ${ }^{2,5}$, Ignacio Escobar ${ }^{6}$, Frederic Manresa ${ }^{1,2}$, Jordi Dorca ${ }^{1,2}$, Daniel Navajas ${ }^{3,7}$, Jordi Alcaraz ${ }^{3,7+}$ and Maria Molina-Molina ${ }^{1,2,7+}$

\begin{abstract}
Background: There is growing interest in the development of cell culture assays that enable the rigidity of the extracellular matrix to be increased. A promising approach is based on three-dimensional collagen type I matrices that are stiffened by cross-linking through non-enzymatic glycation with reducing sugars.

Methods: The present study evaluated the biomechanical changes in the non-enzymatically glycated type I collagen matrices, including collagen organization, the advanced glycation end products formation and stiffness achievement. Gels were glycated with ribose at different concentrations $(0,5,15,30$ and $240 \mathrm{mM})$. The viability and the phenotypic changes of primary human lung fibroblasts cultured within the non-enzymatically glycated gels were also evaluated along three consecutive weeks. Statistical tests used for data analyze were Mann-Whitney U, Kruskal Wallis, Student's $t$-test, two-way ANOVA, multivariate ANOVA, linear regression test and mixed linear model.

Results: Our findings indicated that the process of collagen glycation increases the stiffness of the matrices and generates advanced glycation end products in a ribose concentration-dependent manner. Furthermore, we identified optimal ribose concentrations and media conditions for cell viability and growth within the glycated matrices. The

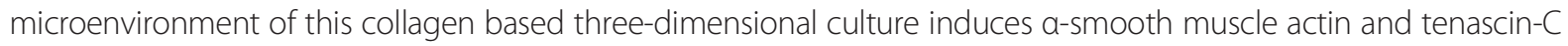
fibroblast protein expression. Finally, a progressive contractile phenotype cell differentiation was associated with the contraction of these gels.
\end{abstract}

Conclusions: The use of non-enzymatic glycation with a low ribose concentration may provide a suitable model with a mechanic and oxidative modified environment with cells embedded in it, which allowed cell proliferation and induced fibroblast phenotypic changes. Such culture model could be appropriate for investigations of the behavior and phenotypic changes in cells that occur during lung fibrosis as well as for testing different antifibrotic therapies in vitro.

Keywords: Three-dimensional matrices, Collagen, Fibroblasts, Alpha-smooth muscle actin, Non-enzymatic glycation, Advanced glycation end products (AGEs), Viability, Stiffness, Contractility, Lung fibrosis

\footnotetext{
* Correspondence: vvicens@hotmail.com

${ }^{\dagger}$ Equal contributors

'Department of Pneumology, Unit of Interstitial Lung Diseases, University

Hospital of Bellvitge, Barcelona, Spain

${ }^{2}$ Pneumology Research Group, IDIBELL, University of Barcelona, Barcelona,

Spain

Full list of author information is available at the end of the article
}

\section{Biomed Central}

(c) 2015 Vicens-Zygmunt et al. This is an Open Access article distributed under the terms of the Creative Commons Attribution License (http://creativecommons.org/licenses/by/4.0), which permits unrestricted use, distribution, and reproduction in any medium, provided the original work is properly credited. The Creative Commons Public Domain Dedication waiver (http:// creativecommons.org/publicdomain/zero/1.0/) applies to the data made available in this article, unless otherwise stated. 


\section{Background}

Pulmonary extracellular matrix (ECM) is a complex mesh of proteins, proteoglycans and glycosaminoglycans, which contains the cells and participates in tissue's homeostasis and repair. Active lung fibroblasts, myofibroblasts and other cell types, are normally surrounded by this fibrous three-dimensional (3D) extracellular matrix and are mainly responsible for the synthesis, secretion and degradation of the ECM components. Moreover, these cells are responsible for the correct turnover of ECM proteins, preserving the lung architecture and function [1]. However, most in vitro studies of fibroblasts behavior have been performed using conventional two-dimensional (2D) cultures, which lack the structural three-dimensionality provided by the ECM in the original tissue. This limitation is important because it can cause the loss or change of important tissue-specific cell functions due to the lack of essential ECM signals [2, 3]. A suitable alternative to overcome this limitation is 3D cultures, in which cells are embedded within ECM gels. Studies using 3D cultures have shown that the ECM influences cell behavior through mechanical interactions and biochemical signals [3-6]. Moreover, these studies have clearly shown that cell functions and phenotypes depend on the structure of the microenvironment, such as the ECM [2-4] and have revealed the profound impact of extracellular forces on the behavior of fibroblasts and other cell types $[3,7,8]$.

On the other hand, fibrotic lung diseases, such as idiopathic pulmonary fibrosis (IPF), are characterized by an excessive ECM deposition and the expansion of the fibroblast/myofibroblast population leading to an increased parenchyma stiffness and retraction, with final lung destruction and patient death [9-12]. In this context, the increased matrix stiffening observed in the lung fibrotic process may be a critical fibrogenesis driving factor $[13,14]$. Unfortunately, suitable 3D culture assays for the study of fibrotic lung diseases and other aging disorders, primarily mimicking matrix stiffness are scanty.

Therefore, there is growing interest in developing 3D culture assays that enable increasing the rigidity of the ECM mimicking the situation observed during fibrotic processes in vivo. In some 3D culture assays based on collagen gels, the rigidity of the ECM is modified by changing the ECM concentration [15]. Alternatively, ECM stiffness can be changed by increasing the crosslinking through non-enzymatic glycation with reducing sugars, which cause the accumulation of the final products of glycation, i.e., the advanced glycation end products (AGEs) [3, 5, 16-24]. Interestingly, an excess of AGEs in aged human tissues has been observed to stiffen tissues in different degenerative diseases [25] and may accelerate protein oxidation, altering their structure and threatening their function [23, 24]. Therefore, various physical characteristics of the fibrotic lung tissue, such as reduced elastic recoil [2], decreased matrix degradation [21, 22, 26, 27], oxidative ECM protein damage [28], may be related to the accumulation of AGEs, contributing to the acceleration of the fibrotic process. However, the effects of non-enzymatic glycation on collagen gels and the resulting behavior of lung fibroblasts remain largely unknown.

Thus, the aims of this study were: 1) to develop an experimental culture model system that recreate the biomechanical and three-dimensional conditions of fibrotic lungs, and 2) to examine the cellular viability and biomechanical changes in the ECM, including AGE formation and stiffening, in these non-enzymatically glycated collagen gels. This model may facilitate the experimental study of the complex cell-extracellular pro-fibrotic interactions, such as those occurring in fibrotic lung diseases, as IPF.

\section{Methods}

\section{Development of non-cellular post-glycated three-dimensional matrix}

The 3D collagen matrices were produced using native type I collagen from bovine dermis (AteloCell, KOKEN, Japan), following a previously standardized protocol [16] with some modifications. Briefly, type I collagen (4 mg/ ml), 1x Dulbecco's modified Eagle medium (DMEM 10x, Sigma-Aldrich, Germany) or 1x phosphate-buffered saline (PBS 10x, Lonza, Switzerland) were mixed on ice, and then the $\mathrm{pH}$ was carefully adjusted to $7.4 \pm 0.2$ using sterile sodium hydroxide (Sigma-Aldrich). Subsequently, the gels were polymerized at $37^{\circ} \mathrm{C}$ for 30 minutes.

The glycated gels were prepared using a non-enzymatic post-glycation method to modify the biomechanics properties of collagen. Ribose (D-Ribose, Sigma-Aldrich) was used to glycate the matrices according to the literature [19-22]. After gels polymerization, different ribose concentrations $(0,30$ and $240 \mathrm{mM})$ were added in the media (day 0), which were not changed until the fifth day to allow cross-linking between the collagen and the reducing sugar to occur [19-21, 27]. Then, medium without ribose was used, which was changed every two days for twentyone consecutive days.

\section{Physical characteristics of the non-cellular post-glycated three-dimensional matrix Confocal reflectance collagen imaging}

Collagen gels under all of the ribose conditions were prepared in $35 \mathrm{~mm}$ glass-bottom culture dishes (MatTek, USA). The collagen structure was examined using confocal reflection microscopy (CRM) as reported elsewhere [29]. In brief, reflection fluorescence of collagen fibers were visualized by exciting the collagen gels using a $568 \mathrm{~nm}$ laser and collecting the reflected signal of the same wavelength. Images were acquired on the $7^{\text {th }}, 14^{\text {th }}$ 
and $21^{\text {st }}$ days post-polymerization with an inverted confocal laser-scanning microscope (D-Eclipse C1, Nikon, Tokyo, Japan) coupled to an EM-CCD digital camera (C9100, Hamamatsu, Japan) equipped with an ELWD $60 \times / 0.70$ objective (Nikon, Tokyo, Japan) using Metamorph software (Molecular Devices, USA). The same image acquisition parameters were used for all of the gels at each time point. The images were analyzed using Image J program [30].

\section{Advanced glycation end products (AGEs)}

Different experimental conditions were used to produce the post-glycated DMEM and PBS three-dimensional collagen matrices as follows: ribose at $0,5,15,30$ or $240 \mathrm{mM}$ and Fetal Bovine Serum (FBS) at 0, 1 or $10 \%$ was added to the media on the day 0 . The level of fluorescent advanced glycation end products (AGEs) generated in collagen matrices was determined by an indirect measure in dark 96-well sterile plates (Nunc, Denmark) using a FLUOstar OPTIMA plate reader (BMG Labtech, Germany) at ex/em: 360/ $440 \mathrm{~nm}$ wavelength $[20,21,27,28,31,32]$, on the $1^{\text {st }}, 7^{\text {th }}$, $14^{\text {th }}$ and $21^{\text {st }}$ days post-polymerization. The level of matrices and media autofluorescence was individually analyzed.

\section{Gel mechanical measurements by atomic force microscopy (AFM)}

Post-glycated 3D collagen matrices were elaborated as explained above using the same conditions of collagen fibers configuration (confocal reflectance imaging). The riboseinduced mechanical alterations in the collagen gels were examined on the $7^{\text {th }}, 14^{\text {th }}$ and $21^{\text {st }}$ days by assessing their Young's elastic modulus, $E$, which is indicative of gel's resistance to deformation. E was measured using a standalone AFM (Bioscope, Veeco, USA) coupled to an inverted optical microscope as previously described [33]. Briefly, the AFM measurements were taken using low spring constant cantilevers with pyramidal tips (nominal $k=0.01 \mathrm{~N} / \mathrm{m}$ ) (Microlever, Veeco), which were calibrated using the thermal noise method [34]. For each gel location, three force vs. piezo displacement curves ( $F-z$ curves) were acquired using a moderate loading force $(\sim 1 \mathrm{nN})$. For each gel location, $E$ and the extent of gel indentation $(d)$ were computed as the averages of the values obtained by least-squares fitting of a contact elastic model to each set of three $F-z$ curves, as reported elsewhere [35]. The same protocol was applied on at least 9 random gel locations. For each treatment, the $E$ data were normalized using the corresponding value obtained from $0 \mathrm{mM}$ ribose gel at the $7^{\text {th }}$ day.

\section{Effects of post-glycated matrices on primary human normal lung fibroblasts \\ Ethics Statement}

This study involved the analysis of human clinical samples. Normal human lung tissues were obtained from lung biopsies from patients with pneumothorax and no history of tobacco use, diabetes mellitus or any other pathology and that were histologically normal and without infection. Informed written consent was obtained from all patients. The investigation project and protocol were approved by the Ethics Committee of our center (ref. PR202/ 08, CEIC, Institute of Investigation of Bellvitge (IDIBELL), Barcelona, Spain).

\section{Cell culture}

The primary human normal lung fibroblasts were isolated from lung biopsies, following the standard methods described in the literature [36]. Briefly, $1 \mathrm{~mm}^{2}$ fragments of tissue were incubated under sterile conditions in DMEM supplemented with $10 \%$ FBS (Gibco, UK), $100 \mathrm{IU} / \mathrm{mL}$ penicillin (Gibco), $100 \mu \mathrm{g} / \mathrm{mL}$ streptomycin (Gibco) and $2 \mu \mathrm{g} / \mathrm{mL}$ amphotericin B (Sigma-Aldrich). The fibroblasts cultures were maintained in a $5 \% \mathrm{CO}_{2}$ humidified atmosphere at $37{ }^{\circ} \mathrm{C}$. After two-three weeks of culture cells were attached to the plate. Unattached cells were eliminated by changing the media. When reaching the confluence, the morphology of cells were fibroblasts type, and resulted positive for vimentin and negative for alpha-sma markers, indicating the mesenchymal origin (Additional file 1). Fibroblasts were then trypsinized (0.05\% trypsin-EDTA, Gibco) and cryopreserved using standard methods and used at passages (3-5) for culturing within the post-glycated matrices.

\section{Fibroblasts culture within the post-glycated three-dimensional collagen type I matrices}

Type I collagen matrices were prepared as explained before. The primary normal fibroblasts were added and mixed with the collagen before polymerization of the gel. Cells were cultured in 3D post-glycated DMEM collagen matrices in sterile 96-well plates (TPP, Switzerland) at an initial concentration of $15 \times 10^{3}$ cells/gel. After polymerization of the matrices, media with different concentration of ribose and FBS was added $(5,15,30$ and $240 \mathrm{mM}$ of ribose and 0,1 and $10 \%$ of FBS). Cell viability and phenotype changes were evaluated on the $7^{\text {th }}, 14^{\text {th }}$ and $21^{\text {st }}$ days of culture. Analyze of cell viability was adjusted to day 1 and the results were shown since the $7^{\text {th }}$ day to allow cell stabilization and adaptation into the glycated 3D gels. The results were evaluated from the $7^{\text {th }}$ day at different time-points and conditions because until the $5^{\text {th }}$ day the media was not changed to permit collagen cross-links.

\section{Fibroblast viability}

The viability of the fibroblasts growing within the postglycated 3D collagen type I matrices was assessed using a metabolic test (AlamarBlue assay, Invitrogen, UK) and a staining method that distinguishes viable and non-viable cells (LIVE/DEAD viability/cytotoxicity kit, Invitrogen) on 
the $7^{\text {th }}, 14^{\text {th }}$ and $21^{\text {st }}$ days, following the manufacturer's recommendations. The AlamarBlue assay, which is normally used in 2D cultures, required preliminary tests for use in the 3D collagen matrices. After testing AlamarBlue at several concentrations and incubation times for twentyone days, incubation time of $8 \mathrm{~h}$ and concentration of $1 /$ 10 were used in all viability experiments. Then, the assay was conducted according to the manufacturer's recommendations. The cell fluorescence was measured using a microplate reader (FLUOstar OPTIMA, BMG Labtech) at ex/em: 550/590 nm wavelengths. The LIVE/ DEAD viability/cytotoxicity reagents stain viable cells in green (Calcein acetoxymethyl ester; Ca AM (ex 495/ em $515 \mathrm{~nm}$ wavelengths)) and non-viable cells in red (ethidium homodimer-1; Eth-D1 (ex 495/em 635 nm wavelength). Images of stained sections were acquired using a Leica TCS-SL filter-free spectral confocal laser scanning microscope (Leica Microsystems, Mannheim, Germany) equipped with a $488 \mathrm{~nm}$ argon laser using a $10 \mathrm{x}$ dry objective (0.3 numerical aperture). Threedimensional image assembly was performed using the fiji-win32 program (Image J). The cells were typified as live or dead using manual counting by two observers. An additional movie shows the cellular distribution in 3D-matrices after stained with Calcein and Ethidium stains (see Additional file 2). An additional image of fibroblasts morphology, when they are cultured into the DMEM and PBS matrices at different FBS concentrations $(0,1$ and $10 \%)$, is available as Additional file 3 .

\section{a-smooth muscle actin gene expression}

RNA extraction was performed using the guanidiniumthiocyanate-phenol-chloroform method (TRIzol, Invitrogen), according to the manufacturer's recommendation. First, the matrices were placed in TRIzol Reagent and disrupted using a tissue homogenizer. To eliminate the genomic DNA, the RNA was treated with DNAse I (Invitrogen). One microgram of total RNA was reverse transcribed to cDNA using a High Capacity cDNA Reverse Transcription kit (Applied Biosystems, $\mathrm{UK}) . \alpha$-smooth muscle actin ( $\alpha$-SMA) gene expression was evaluated using real-time quantitative reverse transcription-polymerase chain reaction (qPCR) with the TaqMan Gene Expression master mix (7900 HT, Applied Biosystems). The results were analyzed by the $\Delta \Delta \mathrm{Ct}$ method, normalized with two endogenous housekeeping genes (Eukaryotic 18S rRNA, 18S and DNA-directed RNA polymerase II, RPII).

\section{a-smooth muscle actin Western Blot}

Protein extraction from the matrices was performed according to the Heidebrecht protocol with few modifications [37]. The matrices were rinsed with iced-cold PBS, and the total cellular protein extracts were prepared using a radioimmunoprecipitation assay buffer (RIPA, Sigma-Aldrich) containing phosphatase and protease inhibitor cocktail (Sigma-Aldrich); the samples were sonicated and then frozen at $-80^{\circ} \mathrm{C}$ until protein quantification was performed. Prior to performing the protein quantification, a 2-D clean-up (GE Healthcare Life Science, Germany) was conducted. Protein quantification was performed using a BCA Protein Assay Reagent (Thermo scientific, Germany) following the manufacturer's instructions. Thirty micrograms of protein extract was loaded to SDS-polyacrylamide gel electrophoresis (SDS-PAGE, Mini-PROTEAN ${ }^{\circ} \mathrm{TGX}^{\mathrm{TM}}$ gels, Bio-Rad Laboratories, USA). The proteins were transferred to Trans-Blot ${ }^{\circ}$ Turbo ${ }^{\mathrm{m}}$ Mini Nitrocellulose Transfer Packs (Bio-Rad) using a Trans-Blot ${ }^{\circ}$ Turbo $^{\text {Ts }}$ Transfer Starter System (Bio-Rad). The membranes were blocked using $5 \%$ BSA (bovine serum albumin, Sigma-Aldrich) in TBST (Tris-buffered saline with $0.1 \%$ Tween 20 ) for $1 \mathrm{~h}$; incubated with the primary antibodies: $\alpha$-SMA (1:500, Sigma-Aldrich) and $\alpha$-tubulin (1:1000, SigmaAldrich) for $1 \mathrm{~h}$ and finally incubated with a secondary anti-mouse IgG antibody conjugated with horseradish peroxidase (1:1000, HRP, Dako, Denmark) for $1 \mathrm{~h}$ at room temperature. After each antibody incubation step, the membranes were washed three times using TBST for 10 minutes each. The bands were visualized with enhanced chemiluminescence using Clarity ${ }^{\mathrm{m}}{ }^{\mathrm{m}}$ Western ECL Substrate (Bio-Rad), and images were captured using a LAS-3000 Imaging System (Fujifilm Holdings Corporation, Japan). As a band of $66 \mathrm{KDa}$ was always present in cellular and acellular matrices, an incubation with the three primary antibodies together for $1 \mathrm{~h}$ (bovine albumin (1:8000, Abcam), $\alpha$-SMA (1:500, Sigma-Aldrich) and $\alpha$-tubulin (1:1000, Sigma-Aldrich)) was performed confirming that the band observed at $66 \mathrm{KDa}$ was albumin, probably due to the difficulties in rinsing all the media with FBS contained in the matrices prior to protein extraction (data not shown).

Western blot densitometry was performed using MultiGauge image software (Fujifilm) by normalizing the values for $\alpha$-SMA expression to the respective value of $\alpha$-tubulin for each sample.

\section{Tenascin-C expression}

To assess the expression of the pro-fibrotic protein Tenascin-C (TNC) produced by fibroblasts, an ELISA using a Human Tenascin-C Large Assay Kit (FN III-C, IBL International, Germany) was performed following the manufacturer's instructions.

TNC was evaluated from the supernatants of the DMEM matrices when gel contraction was observed (i.e. when $10 \%$ of FBS was used). The precoated plate was read in Multiskan EX (Thermo Scientific, USA) and measured at $450 \mathrm{~nm}$. 


\section{Statistical analyses}

The data are expressed as the mean values \pm SD from three independent experiments. Differences between the control and experimental conditions were assessed using different tests. Data with non-normal distribution were analyzed using non-parametrical Mann-Whitney $U$ and Kruskal Wallis tests. When the data attained a normal distribution, Student's $t$-test, a two-way ANOVA, a multivariate ANOVA and a linear regression test were used. To evaluate the cell viability data, a mixed linear model was used. Statistical significance was considered when the $\mathrm{p}$ value was less than 0.05 . We performed the analyses using SPSS 15.0 software (IBM SPSS statistics, USA). For the calculations regarding cell viability, free statistical software was used (www.r-project.org) with the nmle package for the mixed linear models.

\section{Results}

Physical characteristics of the non-cellular post-glycated three-dimensional

Using CRM we examined the morphological and structural modifications of type I collagen post-glycated fibers (reflection fluorescence). Different changes occurred depending on the medium used in the preparation of the matrices (DMEM or PBS). DMEM matrices exhibited large, thick fibers that formed aggregates (Fig. 1a), while PBS matrices displayed short, thin collagen fibers with no evidence of aggregation (Fig. 1b). An increased intensity of collagen reflection fluorescence was observed in all the DMEM matrices with the highest ribose concentration (240 mM). However, this phenomenon did not occur in PBS matrices. This different reflection fluorescence intensity in DMEM and PBS matrices was attributed to different pattern of collagen fibers organization depending on the substrate used (DMEM or PBS).

To indirectly assess the extent of AGEs formation, we measured the autofluorescence intensity of DMEM and PBS matrices with different FBS concentrations at the wavelength of fluorescent AGEs (ex/em 360/ $440 \mathrm{~nm})$ by a plate reader as described in the literature $[20,21,27,28,31,32]$. As shown in Fig. 2 (a and $b$ ), the content of AGEs increased gradually in a ribose concentration-dependent manner in both conditions, DMEM and PBS $(\mathrm{p}<0.05)$, independently of the serum concentration $(\mathrm{p}>0.05)$. The highest value was found at the highest ribose concentration (240 mM, p <0.01). An autofluorescence peak was found at $7^{\text {th }}$ day $(\mathrm{p}<0.01)$ in all conditions. Then, less autofluorescence was observed for all the matrices at day 14 and 21, probably due to a decreased amount of AGEs formation after changing the media every 2 days. Interestingly, autofluorescence measurements revealed that DMEM matrices (Fig. 2a) were more autofluorescent than PBS matrices (Fig. 2b) at days 1 and 7 ( $\mathrm{p}<0.05$ in practically all conditions). Nevertheless, PBS matrices became more autofluorescent than DMEM ones after the $14^{\text {th }}$ day (statistically significant in practically all conditions for FBS $1 \%$ and $10 \%$ ). Because the accumulation of AGEs generated by nonenzymatic glycation induces modifications and cross-links that stiffen human tissue proteins [22, 25], we examined using the mechanical changes in glycated matrices at the micrometer scale by measuring the Young's elastic modulus (E) through AFM (Fig. 3). The E value of the control gels $(0 \mathrm{mM}$ ribose $)$ at day 7 was $1.6 \pm 0.3$ and $0.9 \pm 0.5 \mathrm{kPa}$ in DMEM and PBS post-glycated matrices (0 \% FBS),

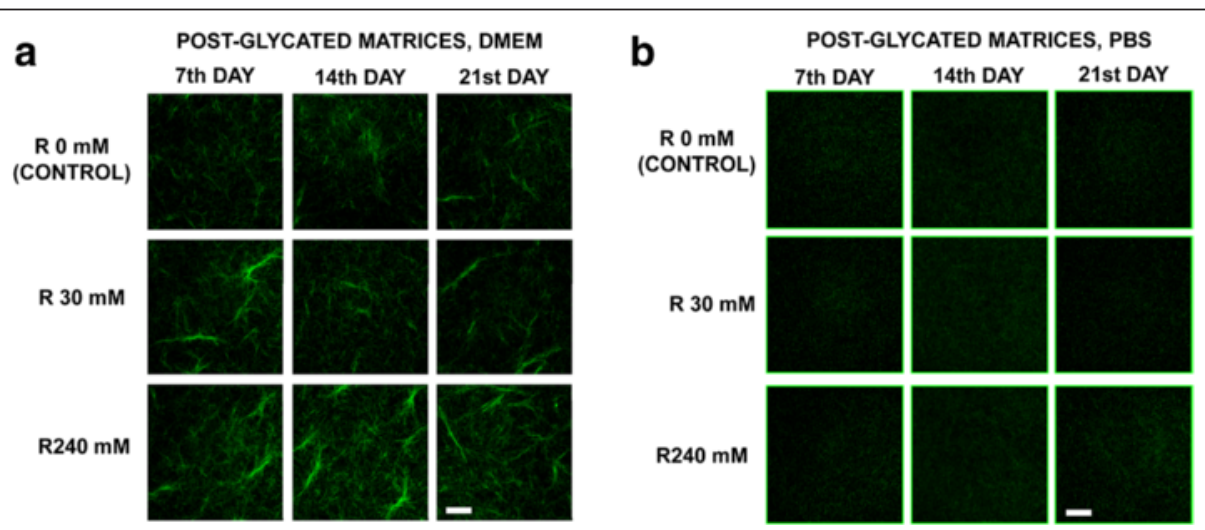

Fig. 1 Increased collagen type I fiber reflection fluorescence with non-enzymatic glycation. Collagen type I fiber conformation observed with CRM (laser ex/em 568/568 nm) at different ribose (R) concentration over a period of twenty-one days. a. In post-glycated DMEM matrices, collagen type I fibers formed aggregates and reflected more fluorescence with elevated R concentrations. $\mathbf{b}$. In post-glycated PBS matrices, collagen type I fibers were short, thin and homogeneous, with no increase of reflected fluorescence with higher R concentration $(240 \mathrm{mM})$. $\mathbf{a}$ and $\mathbf{b}$. Reflection fluorescence of non-glycated matrices (controls) was done to the reflective properties of the collagen. Time seems to not affect the reflection fluorescence of collagen. The increase in CRM signal in DMEM gels could also be contributed by the increased aggregation of collagen fibers observed in these gels, perhaps because the presence of glucose. The scale bar corresponds to $40 \mu \mathrm{m}$. CRM = Confocal reflection microscope; DMEM = Dulbecco's modified Eagle medium; PBS = Phosphate-buffered saline 


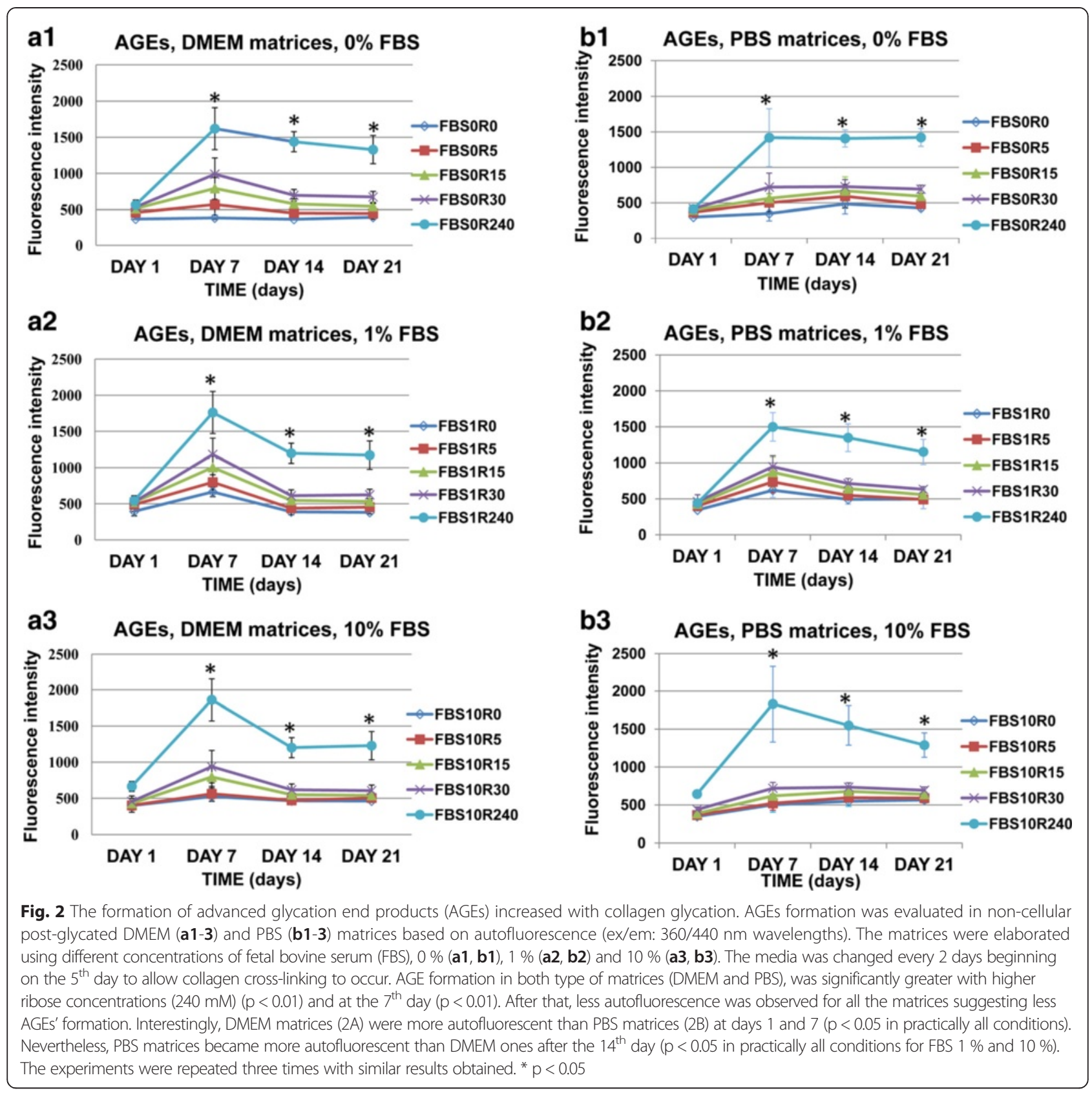

respectively. All subsequent $\mathrm{E}$ values were normalized to the corresponding control values at day 7. Our results revealed that both DMEM and PBS matrices stiffened in a ribose-dependent manner with respect to the control nonglycated gels $(\mathrm{p}<0.01)$. The highest value of stiffness was reached at day $21^{\text {st }}$ for PBS matrices as shown in Table 1 (absolute E value: $2.5 \pm 1.35 \mathrm{KPa}$ ). Nonetheless, the maximum point of stiffness was not always at the end of the experiment. Fold stiffness in DMEM gels remained rather unaltered after day $14^{\text {th }}$. In contrast we observed a moderate rise in fold gel stiffness in PBS gels up to $21^{\text {st }}$ day (Fig. 3a and b). Consequently, stiffness of the matrix was greater after the $14^{\text {th }}$ day of post-polymerization. However, the basal stiffness values in control gels ( $0 \mathrm{mM}$ ribose) at day $7^{\text {th }}$ were higher in DMEM than in PBS gels, perhaps because of glucose present in DMEM.

Effects of post-glycated matrices on primary human normal lung fibroblasts

\section{Fibroblast viability}

The fibroblast viability in the glycated 3D collagen matrices at different FBS concentrations was determined quantitatively using the AlamarBlue assay, which assesses the extent of mitochondrial activity via fluorescence (redox 

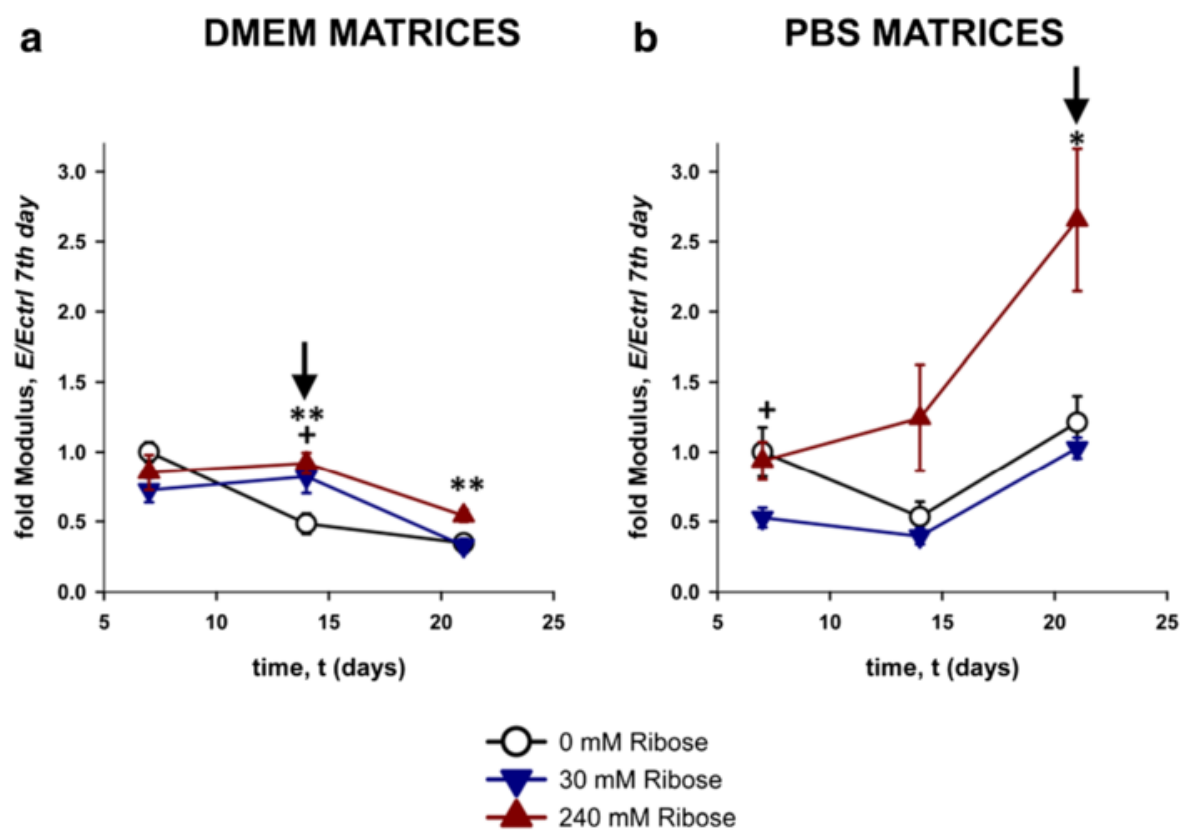

NOTE: E/Ectrl $7^{\text {th }}$ day: Elastic modulus (E) normalized to $E$ control (Ectrl) at the $7^{\text {th }}$ day.

Fig. 3 Collagen post-glycation increased the matrix stiffness. The stiffness of the non-cellular post-glycated matrices was measured using atomic force microscopy at days 7, 14 and 21. The values were normalized using that of the non-glycated matrices, i.e. control matrices $(0 \mathrm{mM}$ of ribose (R)) at the $7^{\text {th }}$ day. The black arrows indicate the $\mathrm{R}$ concentration that rendered the collagen gels stiffer than the non-glycated gel at the $7^{\text {th }}$ day. a. DMEM matrices. Collagen gels stiffened in a R dependent manner at the $14^{\text {th }}$ day after glycation at 30 and $240 \mathrm{mM}$ of ribose respect to the control non-glycated gels $(p<0.01)$. b. PBS matrices. The collagen gels stiffened with $240 \mathrm{mM}$ of ribose at the $21^{\text {st }}$ day after glycation $(p<0.01)$. a and $\mathbf{b}$. This different stiffening dynamics suggests different cross-linking rates between these gels. The glucose present in DMEM could play a role in the stiffness developed, which could render a higher basal level of glycation before ribose treatment. Accordingly, the non-glycated DMEM gels (controls) showed greater stiffness than the glycated matrices at the $7^{\text {th }}$ day. Phenomenon not observed in PBS matrices. The highest $R$ concentration (240 mM) led to the stiffest conformation of both types of matrices $(p<0.01)$. $p$-values for $30 \mathrm{mM}$ of ribose: $+(0.01<p<0.05)$, $++(p<0.01)$; $p$-values for $240 \mathrm{mM}$ of ribose: ${ }^{*}(0.01<p<0.05),{ }^{* *}(p<0.01)$

reaction, Fig. 4a), and confirmed qualitatively by differential staining of live and dead cells visualized using confocal microscopy (Fig. 4b).

In our study, the fluorescence intensity data revealed a marked decrease in fibroblast viability at the highest ribose concentration $(240 \mathrm{mM})$ under all of the gel conditions independently of the substrate FBS content $(\mathrm{p}<$ 0.01) (Fig. 4a and b), suggesting a cytotoxic effect of ribose at high concentration. Nevertheless, cells proliferated and survived during 21 days of culture with 5, 15 and $30 \mathrm{mM}$ ribose concentration when $10 \%$ of FBS was used (Fig. 4 a3). No statistical differences in cell viability were observed respect to the control, $0 \mathrm{mM}$ ribose when $0 \%$ of FBS was used ( $p>0.05)$, nor for $1 \%$ too ( $p>0.05)$. A strong effect on cell growth was observed when comparing fibroblasts cultured in matrices with serum with matrices without serum over the period from the $7^{\text {th }}$ to the $21^{\text {st }}$ day, which was independent of the ribose concentration ( $\mathrm{p}<0.01$ for $1 \%$ and $10 \%$ FBS, respectively).

On the other hand, to confirm the results of cell viability and avoid the possible effect of the reducing sugar to the redox reaction of the AlamarBlue assay, data from non-cellular matrices were analyzed (Additional file 4). Results showed that the fluorescence intensity from noncellular matrices was significantly higher at $240 \mathrm{mM}$ of ribose concentration $(\mathrm{p}<0.01)$ and was independent of the use of serum $(p>0.05)$ (Additional file 4). Therefore, the observed increase in the fluorescence of the cellular matrices depended on the cell viability, which increased with serum. Then, the best conditions for allowing cell to grow inside the glycated collagen gels up to 21 days are at 5 and $15 \mathrm{mM}$ of ribose and $10 \%$ of FBS.

In addition, images taken using a CRM confirmed that the cells had proliferated, with an increase in the number of viable cells when FBS and low ribose concentrations were used (Fig. 4 b2 and b3) and that cells died with the highest ribose concentration from the first days (data shown in Fig. 4 b1-3 from the $7^{\text {th }}$ day). Moreover, matrix contraction was observed in the lattices with increased cell growth $(<15 \mathrm{mM}$ ribose and $10 \% \mathrm{FBS}$ ) between the $14^{\text {th }}$ and $21^{\text {st }}$ days of culture (Fig. 4 b3). 
Table 1 Summary results from the post-glycated three-dimensional collagen matrices

\begin{tabular}{|c|c|c|c|c|}
\hline \multicolumn{3}{|l|}{ Types matrices } & PBS & DMEM \\
\hline \multicolumn{3}{|c|}{$\begin{array}{l}\text { Fiber collagen I reflection fluorescence } \\
\text { (ex/em: 568/568 nm) }\end{array}$} & $\begin{array}{l}\text { Short, thin, homogeny collagen fibers with no evidence } \\
\text { of aggregation nor increment of reflection collagen } \\
\text { fluorescence. }\end{array}$ & $\begin{array}{l}\text { Large heterogenic thick fibers that formed aggregates. Increase of reflection } \\
\text { collagen fluorescence at higher ribose concentration. }\end{array}$ \\
\hline \multirow{5}{*}{$\begin{array}{l}\text { Stiffness (absolute } \\
\text { values, } \mathrm{KPa}+/-\mathrm{SD} \text { ) }\end{array}$} & $7^{\text {th }}$ day & $0 \mathrm{mM}$ & $0.9+/-0.5$ & $1.6+/-0.3$ \\
\hline & $14^{\text {th }}$ day & $30 \mathrm{mM}$ & $0.47+/-0.31$ & $1.33+/-0.51$ \\
\hline & & $240 \mathrm{mM}$ & $1.17+/-087$ & $1.71+/-0.72$ \\
\hline & $21^{\mathrm{st}}$ & $30 \mathrm{mM}$ & $0.97+/-0.16$ & $0.53+/-0.21$ \\
\hline & & $240 \mathrm{mM}$ & $2.5+/-1.35$ & $1.03+/-0.43$ \\
\hline \multirow[t]{9}{*}{ Viability } & \multirow{4}{*}{\multicolumn{2}{|c|}{$\begin{array}{l}\text { AlamarBlue Assay } \\
\text { Fluorescence (ex/em: } \\
550 / 590 \mathrm{~nm})\end{array}$}} & Data not shown & \\
\hline & & & [Ribose] & [Ribose] \\
\hline & & & $240 \mathrm{mM} \rightarrow$ cell death & $240 \mathrm{mM} \rightarrow$ cell death \\
\hline & & & $\leq 30 \mathrm{mM} \rightarrow \uparrow$ mitochondrial metabolism & $\leq 30 \mathrm{mM} \rightarrow \uparrow$ mitochondrial metabolism \\
\hline & \multirow{5}{*}{\multicolumn{2}{|c|}{$\begin{array}{l}\text { Confocal Reflection } \\
\text { Microscopy, live/dead assay } \\
\text { (green/red stain) }\end{array}$}} & Data not shown & \\
\hline & & & [Ribose] & [Ribose] \\
\hline & & & $240 \mathrm{mM} \rightarrow$ cell death & $240 \mathrm{mM} \rightarrow$ cell death \\
\hline & & & $\leq 30 \mathrm{mM} \rightarrow$ Better viability (green stain) & $\leq 30 \mathrm{mM} \rightarrow$ Better viability (green stain) \\
\hline & & & $\begin{array}{l}\text { Cell morphology: round, stellar, short dendritic cells } \\
\text { (See Additional file 3). }\end{array}$ & Cell morphology: spindle, long dendritic cells (See Additional file 3). \\
\hline \multirow{3}{*}{\multicolumn{3}{|c|}{ Gel contraction }} & Data not shown & \\
\hline & & & [Ribose] & [Ribose] \\
\hline & & & $\begin{array}{l}\text { Controls }(0 \mathrm{mM}) \text { : from } 14^{\text {th }} \text { day } \\
5 \mathrm{mM} \text { and } 15 \mathrm{mM} \text { : Between } 14^{\text {th }} \text { and } 21^{\text {st }} \text { days of culture. }\end{array}$ & $5 \mathrm{mM}, 15 \mathrm{mM}$ and controls $(0 \mathrm{mM})$ : between $14^{\text {th }}$ and $21^{\text {st }}$ day of culture. \\
\hline \multirow{2}{*}{\multicolumn{3}{|c|}{$\begin{array}{l}\text { AGEs autoflorescence } \\
\text { (ex/em: } 360 / 440 \mathrm{~nm})\end{array}$}} & At $\uparrow[$ Ribose $] \rightarrow$ autofluorescence increase. & At $\uparrow[$ Ribose $] \rightarrow$ autofluorescence increase. \\
\hline & & & $\begin{array}{l}\text { Higher autofluorescence at the } 14^{\text {th }} \text { and } 21^{\text {st }} \text { day compared } \\
\text { with DMEM matrices }\left(^{*}\right) \text {. }\end{array}$ & Higher autofluorescence at the $1^{\text {st }}$ and $7^{\text {th }}$ day compared with PBS matrices $\left(^{*}\right)$ \\
\hline \multirow[t]{3}{*}{ Protein synthesis } & \multirow{2}{*}{\multicolumn{2}{|c|}{$\begin{array}{l}\text { a-smooth muscle actin } \\
\text { (a-SMA) }\end{array}$}} & NA & Gene expression ( $21^{\text {st }}$ day): at $5\left(^{*}\right)$ and $15 \mathrm{mM}$ of [Ribose] and controls. \\
\hline & & & & $\begin{array}{l}\text { Protein expression ( } 14^{\text {th }} \text { and } 21^{\text {st }} \text { days): in all conditions, particularly with } 5 \text { and } \\
15 \mathrm{mM} \text { of [Ribose]. }\end{array}$ \\
\hline & \multicolumn{2}{|c|}{ Tenascin-C (TNC) } & NA & Protein expression: $\uparrow$ in a time-dependent manner at 14 and 21 days $(*)$. \\
\hline
\end{tabular}




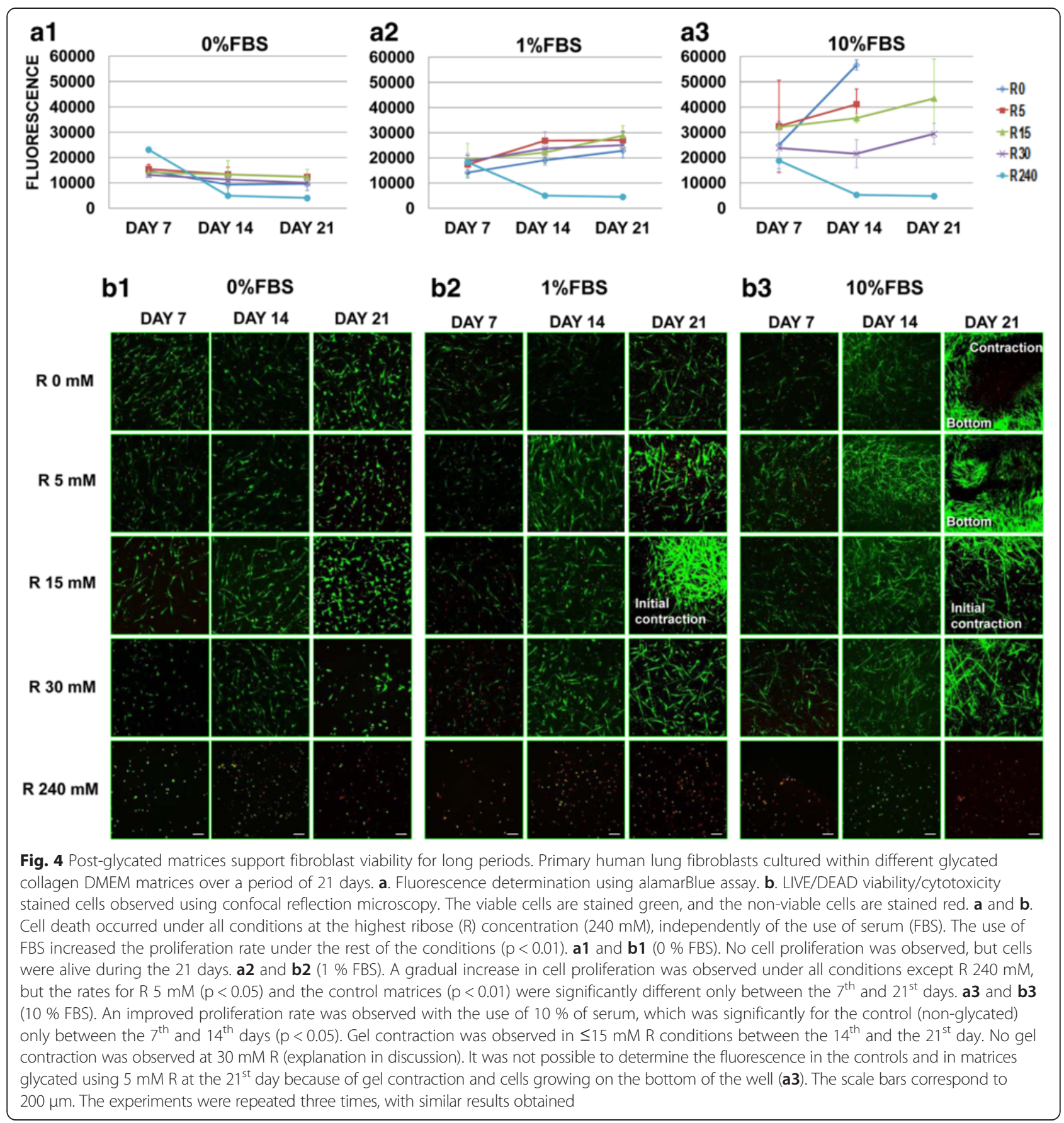

\section{Fibroblast differentiation and synthesis}

To evaluate the putative differentiation of fibroblasts to a contractile cell phenotype (myofibroblasts-like), which could contribute to the contraction of the post-glycated DMEM matrices $\alpha$-smooth muscle actin ( $\alpha$-SMA) gene expression and $\alpha$-SMA protein levels were examined. Only contracted matrices were evaluated, i.e. those with $10 \%$ FBS. The cells growing on the bottom of the petri dishes were not analyzed (Fig. 4 b3).
A higher increase of $\alpha$-SMA gene expression was observed in $0-15 \mathrm{mM}$ of ribose at the $21^{\text {st }}$ day (Fig. 5). $\alpha$-SMA protein detection appeared from day $7^{\text {th }}$ in all conditions, with and without ribose, and was significantly increased at days 14 and 21 compared to the $7^{\text {th }}$ day $(\mathrm{p}<0.01)$, which suggests that the induction of $\alpha$-SMA is modified by the 3D microambient 'per se' (Fig. 6).

The supernatants of the DMEM matrices from three independent experiments were analyzed to evaluate the 


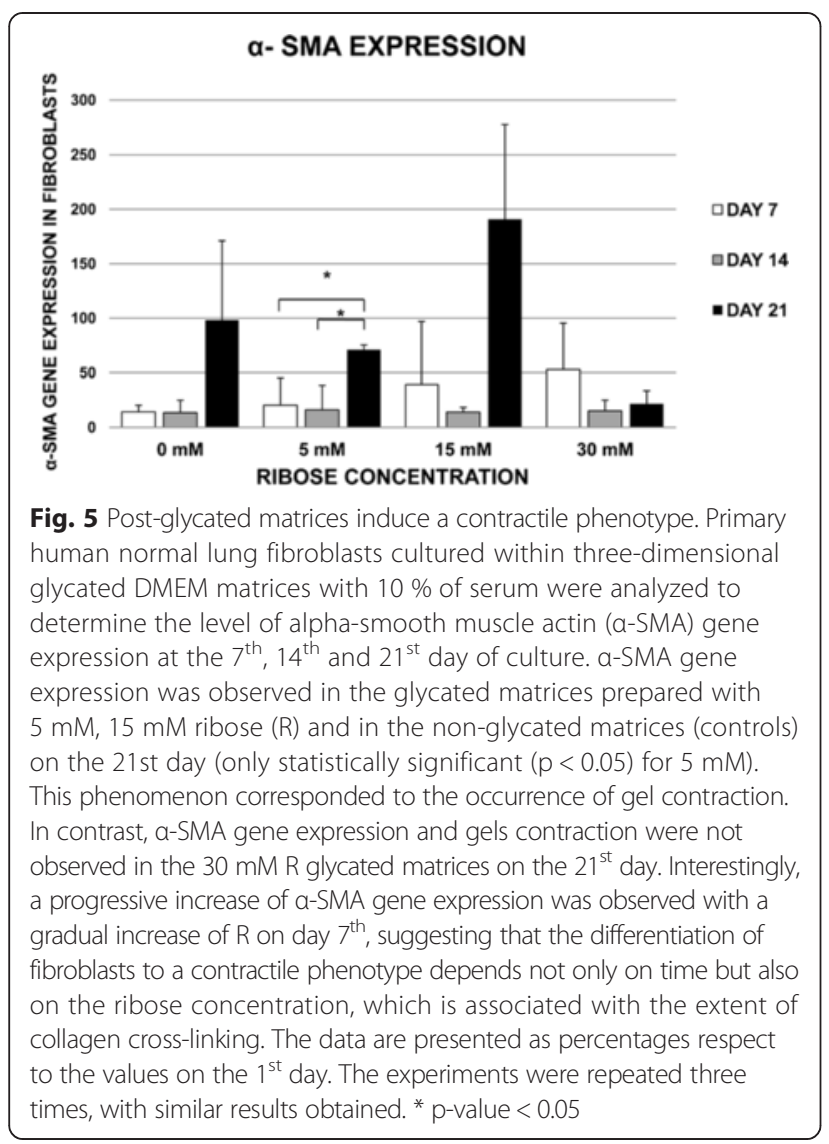

fibroblast tenascin-C (TNC) protein synthesis (Fig. 7). Results showed a progressive increase in the secretion of TNC in all the matrices from the $1^{\text {st }}$ to the $21^{\text {st }}$ day, with statistical differences between the $1^{\text {st }}$ and the $14^{\text {th }}$ day and the $1^{\text {st }}$ and the $21^{\text {st }}$ day $(\mathrm{p}<0.05$ for both comparisons). Although no differences were appreciated between the $14^{\text {th }}$ and the $21^{\text {st }}$ day of culture in most ribose conditions, a higher level of TNC at the $21^{\text {st }}$ day was observed with $30 \mathrm{mM}$ of ribose $(\mathrm{p}=0.08)$. No statistical differences were found between ribosilated and nonribosilated matrices. These results suggest that the 3D microenvironment could be enough to produce changes in the secretion of TNC by normal fibroblasts in a timedependent manner.

\section{Discussion}

Lung tissue fibroblasts are normally surrounded by a 3D ECM and the interaction between fibroblasts and ECM proteins could be crucial in tissue homeostasis and disease. However, most in vitro studies in lung fibrosis have been performed with fibroblasts growing in a plate (2D) or in 3D based on polyacrylamide hydrogels [8, 38, 39] or collagen type I gels $[17,18,27,40]$ with fibroblasts growing on top. Few studies have analyzed the viability of fibroblasts growing within type I collagen matrices [7, 41].
Our study was designed to modify the 3D collagen matrix via non-enzymatic glycation and to analyze the impact of such matrices on fibroblast phenotype and viability growing inside the gel. To our knowledge, there are no previous reports of analyzing fibroblasts viability in glycated DMEM matrices by using two corroborating cell growth methods. We used ribose as a reducing sugar rather than glucose due to the ability of ribose to modify faster the physical and chemical properties of type I collagen gels [21]. Very few studies have used post-glycated collagen matrices with cells growing inside, and none in the field of lung fibrosis [19, 21]. Our novel 3D culture model displayed collagen enrichment and an aging/oxidative microenvironment with increased stiffness, which may be useful for the study of cell behavior and phenotypic changes that depend on pro-fibrotic ECM conditions. Our study points up the best three-dimensional ribosilated matrices conditions to allow primary lung fibroblast viability and growth. Furthermore, the results demonstrate that the 3D collagenated matrices induce fibroblast-to-contractile phenotype differentiation and an increase of TNC synthesis. We observed structural differences in the collagen fibers depending on the medium used in the preparation of the matrices (DMEM or PBS), which may be attributable to the presence of glucose in DMEM. Our results showed that once the matrices have been glycated, the higher ribose concentrations $(240 \mathrm{mM})$ increased the reflectance fluorescence of collagen type I in DMEM matrices (Fig. 1) and the AGEs production (Fig. 2) in agreement with previous published results $[20,21,27]$. However, the ribosedependent increase in CRM signal in DMEM gels could also be contributed by the increased aggregation of collagen fibers observed in these gels, which could locally enhance the reflective properties of the collagen. In contrast, such structure-related differences observed by CRM may not contribute to the autofluorescence measured by the plate reader or to the stiffness results.

The interest of using glycated collagen gels was to resemble the increased stiffness observed in aged and fibrotic lungs [2, 42]. Furthermore, the use of the postglycation method (instead of pre-glycation technique) aimed to approach to the collagen cross-links, which could occur in vivo. Some studies have used nonenzymatic glycation to create stiffer scaffolds with increased mechanical rigidity but none concerned to lung fibrosis [20, 21, 27, 43]. Our results demonstrated that the glycation process stiffened the collagen matrices in a concentration-dependent manner, occurring earlier in the DMEM matrices than in the PBS matrices. To our knowledge, we provide first evidence that glycationinduced collagen gel stiffening depends not only on ribose concentration, but also on the type of substrate solution used (DMEM or PBS). However, these different stiffening dynamics, suggests different cross-linking rates between 


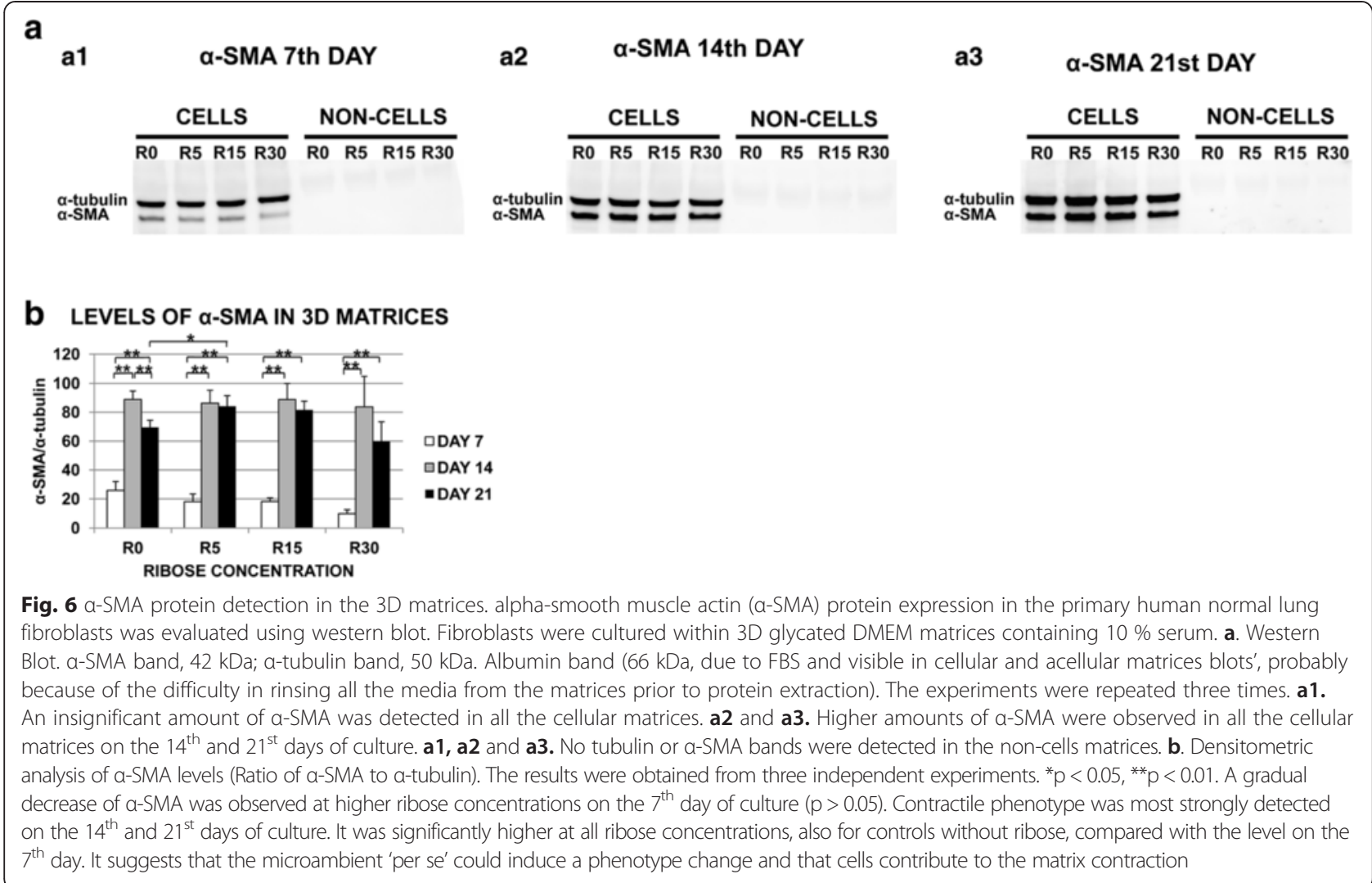

those gels (DMEM compared to PBS), perhaps attributed to the glucose already present in DMEM, which could render a higher basal level of glycation before ribose treatment and to the diameter and length of the cross-linked collagen fibrils [42]. In support of this hypothesis, the basal stiffness values in control gels ( $0 \mathrm{mM}$ of ribose) at day $7^{\text {th }}$ were higher in DMEM than in PBS gels. Our stiffness values were similar to those reported by Roy et al. [20], and slightly higher than those from other authors without cells [27, 43], most likely because of differences in the experimental conditions, such as the method of measure. In contrast, when cells were cultured within the glycated matrices, an elevated Young modulus was observed $[19,21]$. Interestingly, a recent study by Booth et al. [14] showed an increased stiffness of decellularized fibrotic lungs compared with normal lungs, plausibly attributed to the substantial and varied amounts of pro-fibrotic ECM proteins present in the former in addition to collagen. Thus, it is conceivable that cells embedded into the collagen gels would also upregulate the expression of other interstitial proteins, increasing the rigidity of the gel, which will be the focus of future in vitro studies [3, 42]. As a preliminary data, the fibroblasts growing inside our 3D collagen matrices increased the synthesis of TNC, a profibrotic ECM protein. This phenomenon occurred in a time-dependent manner, independently of the ribose concentration. However, the level of TNC was higher in $30 \mathrm{mM}$ ribosilated matrices at the $21^{\text {st }}$ day, suggesting that TNC synthesis by normal fibroblasts was dependent on the cell-type I collagen interactions and also on the indirect effect of ribose on collagen (stiffness, AGEs or collagen cross-links). These observations leads to further studies in order to better explain this effect.

Importantly, the non-enzymatic glycation of collagen resulted in the formation of AGEs, which are related to aging and have been observed to stiffen tissues in different degenerative diseases [22-25]. With age, collagen becomes less soluble [26], more cross-linked and more glycosylated [5]. In studies of aged collagen fibers from different tissues, such as skin and lungs, the presence of AGEs was detected indirectly as an increase in the collagen autofluorescence [31,32]. Our results showed that the change in the autofluorescence of glycated collagen, measured with the specific wavelength of fluorescent AGEs as reported elsewhere [20, 21, 27, 28, 31, 32], was dependent on the formation of AGEs (Fig. 2). Furthermore, we have shown that the collagen autofluorescence was affected by the ribose concentration in a dosedependent manner, with fluorescence increasing when the highest ribose concentration was used. In support of our findings, other groups have reported that the fluorescence of glycated collagen matrices gradually increased with 


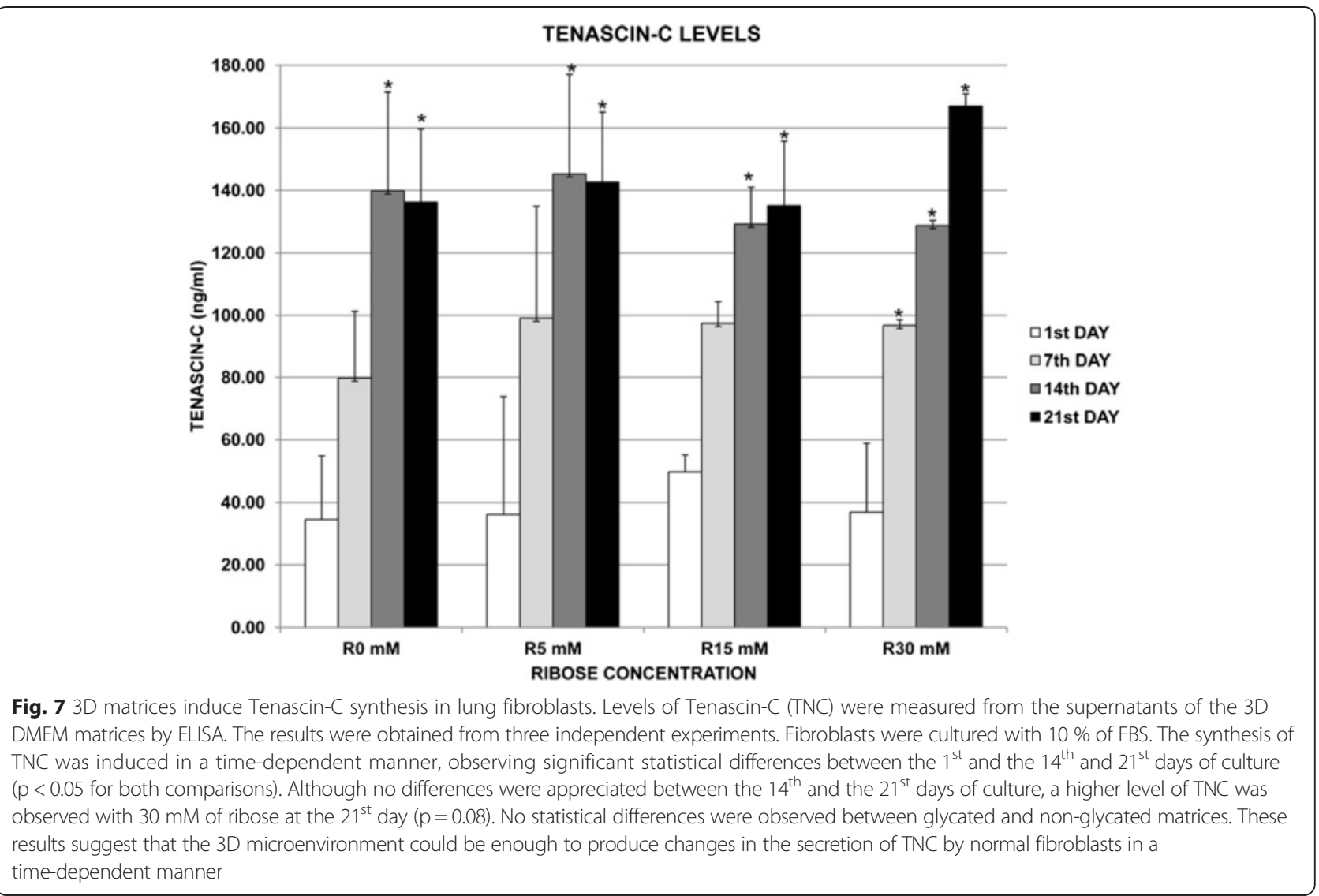

increasing concentrations of reducing sugars independently of the carbohydrate used for glycation [20, 21, 27].

On the other hand, a peak of autofluorescence was always observed at 7th day and then the autofluorescence decreased (days $14^{\text {th }}$ and $21^{\text {st }}$ ), probably because less new AGEs formation after day $7^{\text {th }}$. It could be a consequence of the technical approach, since the media was not changed until the 5th day after post-glycation and then it was changed every two days. This phenomenon could be attributed to the rinse of the matrices with the changes of the media, which would attenuate the formation of new cross-links between the glucose and the collagen. Another possibility would be that the cross-links could be higher at the beginning of the post-glycated matrices reaction. Additionally, our experiments of autofluorescence in PBS and DMEM matrices revealed different cross-linking rates. As DMEM matrices (Fig. 2a) showed more autofluorescence than PBS matrices (Fig. 2b) at days 1 and 7, less autofluorescence from DMEM compared to PBS matrices was observed since the $14^{\text {th }}$ day. These different cross-linking rates could explain the differences in stiffening dynamics between those gels (DMEM and PBS). In agreement with these dynamics, fold stiffness in DMEM gels remained rather unaltered after day 14th. In contrast we observed a moderate rise in fold gel stiffness in PBS gels to the 21st day.

One of the main findings in the present study was the demonstration of the profound effect of the physical and chemical changes of the three-dimensional matrices on the fibroblast phenotype and cell growth. We demonstrated that fibroblasts embedded in the matrices containing low ribose concentrations $(\leq 30 \mathrm{mM})$ were able to proliferate and that the better growth rate was observed using FBS, whereas significant cell mortality was observed in matrices with highest ribose concentration (240 mM) independently of the use of FBS (Fig. 4), most likely because of the increased osmosis [19]. Remarkably, we detected a contractile cell phenotype expressing alpha-smooth muscle actin ( $\alpha$-SMA). This occurrence of the contractile phenotype was related to the contraction of glycated gels using 5 and $15 \mathrm{mM}$ of ribose and to that of the non-glycated matrices between the $14^{\text {th }}$ and $21^{\text {st }}$ days, when $10 \%$ of serum was used (Fig. 4 b3). Remarkably $\alpha$-SMA was induced without adding TGF $\beta 1$, suggesting that the microenvironment 'per se' modifies cell phenotype by increasing cell contractility. Therefore, the experiments of expression and detection of $\alpha$-SMA as a contractile phenotype marker (Figs. 5 and 6 , 
respectively), were performed only in the matrices where the gel contraction was observed, (i.e. when $10 \%$ of FBS was used), to verify if the cells embedded into the matrices could contribute to their contraction. Therefore, it is important to emphasize two messages: 1 ) the induction of $\alpha$-SMA expression and protein level is modified by the microambient and 2) cells contribute to the matrix contraction.

The mechanisms by which cells contract the collagen gels are unclear. Based on previous studies, it is conceivable that as matrix stiffness increases, the fibroblasts develop proportional isometric tension, acquiring prominent actin stress fibers that cause the contraction of the matrices [3, 5, 7, 17, 44, 45]. Nevertheless, fibroblasts that do not surmount the tension of the matrix also develop actin stress fibers, but they do not contract the lattice $[7,17]$. This attribute is relevant to the differences found in $\alpha$-SMA detection and the contraction of our gels depending on the ribose concentration, as occurs with $30 \mathrm{mM}$ of ribose $[7,44]$. In those matrices, the contractile phenotype, $\alpha$-SMA positive (Fig. 6 a2 and a3), did not contract the gels (Fig. 4 b3), probably because the cells did not surmount the tension present in the matrix.

Thus, matrix contraction depends on the presence of fibroblasts $[7,15,45,46]$, the use of serum $[7,44,46]$, and the glycation cross-linking [17]. Additionally, the degree of contraction also depends on the initial collagen concentration [15], the number of cell passages $[7,15,46]$ and the temperature [46].

Even though, we have not performed stiffness experiments when cells are seeded into the matrices, our results suggests that the effect of the matrix on the cells could be because of the matrix biomechanics' microenvironment, the ECM protein cross-links or even either microenvironment factors that can be produced under these conditions. In support of this interpretation, other authors have reported that an increase in the ECM protein concentration, as well as the matrix cross-linking and the mechanical interactions between the ECM and the cells, promote cell proliferation, the acquisition of a contractile phenotype and the modulation of gel contractility, which they attribute to the matrix stiffness $[4-8,15,17,38,40,42,43]$.

\section{Conclusions}

Human lung fibroblasts are able to grow into 3D collagenated and stiffened matrices under specific conditions. The increase of ECM cross-linking via non-enzymatic glycation at low ribose concentrations and the biomechanical interactions between the ECM and the cells embedded in it induces fibroblast phenotype and metabolic changes. Altogether could modulate the gels' contractility. This applicable model with a mechanic and oxidative modified environment could resemble an aging/fibrotic ECM.
Accordingly, such model may be useful for investigating cell behavior and phenotypic changes that occur during the processes of lung fibrosis and aging, as well as for testing different antifibrotic therapies in vitro.

Table 1. Summary results from the post-glycated threedimensional collagen matrices. PBS: phosphate-buffered saline; DMEM: Dulbecco's modified Eagle medium; ex/em: excitation/emission; nm: nanometers; KPa: KiloPascals; SD: Standard deviation; mM: miliMolar; N/A: Not Available; [Ribose]: concentration of ribose; $\downarrow$ : decreased; $\uparrow$ : elevated; $\leq$ : minor or equal; (*) $\mathrm{p}<0,05$.

\section{Additional files}

\section{Additional file 1: Markers of primary human normal lung fibroblast. The primary human normal lung fibroblasts used in this study at passage 3 were analyzed by western blot. a. Tenascin- $C(+)$, E-Cadherin $(-)$, Vimentin $(+++)$ and $\beta$-actin $(+++)$. b. a-tubulin $(++)$ and $\alpha-S M A(+)$. \\ Additional file 2: Movie of fibroblasts distribution when cultured into a 3D collagen matrix. Green cells are live cells. Red cells are dead cells. \\ Additional file 3: Fibroblasts morphology in collagen 3D matrices. Different fibroblast morphology was appreciated into 3D collagen matrices depending on the media conditions (DMEM vs PBS). While with DMEM the fibroblasts were as long dendritic cells and spindle; in PBS, the cells appear round, stellar, and as short dendritic cells. \\ Additional file 4: Fluorescence in cell-free glycated matrices. Fluorescence intensity increased with higher ribose concentrations under all conditions ( $\mathrm{a}, \mathrm{b}$ and $\mathrm{c}$ ) and was independent of the presence of serum ( $b$ and $c$ ).}

\begin{abstract}
Abbreviations
3D: Three-dimensional; AFM: Atomic force microscopy; AGEs: Advanced glycation end products; BSA: Bovine serum albumin; CRM: Confocal Reflection Microscopy; DMEM: Dulbecco's modified Eagle medium; DNA: Deoxyribonucleic acid; E: Young's modulus; ECM: Extracellular matrix; FBS: Fetal bovine serum; IPF: Idiopathic Pulmonary Fibrosis; mM: mili-Molar; PBS: Phosphate-buffered saline; qPCR: Real-time quantitative reverse transcription-polymerase chain reaction; RIPA: Radioimmunoprecipitation assay buffer; RNA: Ribonucleic acid; TNC: Tenascin-C; a-SMA: Alpha-smooth muscle actin.
\end{abstract}

\section{Competing interests}

The authors declare that they have no any competing interests (both financial and non-financial) related to this manuscript.

\section{Authors' contributions}

WZ conceived, designed and performed the experiments; analyzed and interpreted the data; and wrote the first draft of the manuscript. SE conceived, designed and oversaw the experiments and revised the draft of the manuscript. AC performed stiffness measures in three-dimensional matrices. AMW contributed reagents/materials/analysis tools; oversaw the western blot experiments and revised the draft of the manuscript. CM contributed reagents/materials/analysis tools. AJS analyzed the statistical data. RL contributed reagents/materials/analysis tools and reviewed pathology for all interstitial lung diseases patients from lung biopsies. IE contributed tissue samples and contributed reagents/materials/analysis tools. FM contributed reagents/materials/analysis tools. JD contributed reagents/ materials/analysis tools. DN contributed reagents/materials/analysis tools from stiffness experiments. JA conceived, designed and oversaw the stiffness experiments; contributed reagents/materials/analysis tools and revised the draft of the manuscript. MMM conceived, designed and oversaw the experiments; contributed reagents/materials/analysis tools and revised the draft of the manuscript. All authors read and approved the final manuscript. 


\section{Authors' information}

WZ: Ph. Dc., M.D. Pneumologist from University Hospital of Bellvitge from 1, 2 and master in clinical science from University of Barcelona. SE: Ph.D. in biology and biologist in ${ }^{2}$. AC: Ph.D. in biology from ${ }^{3,8}$. AMW: Ph.D. in biology and biologist from ${ }^{2}$. CM: master degree in biology and biologist from ${ }^{2}$. AJS: Ph. DC., M.D. from ${ }^{4}$ with master in Public Health. RL: Ph.D., M.D. Pathologist from ${ }^{2,5}$. IE: Ph.D., M.D. Thoracic surgeon from ${ }^{2,6}$. FM: Ph.D., M.D. Pneumologist and Senior Professor from ${ }^{1,2}$ and Professor in Medicine Faculty from University of Barcelona. JD: Ph.D., Clinical Director of respiratory diseases from University Hospital of Bellvitge, M.D. Pneumologist in ', Group Leader from ${ }^{2}$ and Professor in Medicine Faculty from University of Barcelona. DN: Ph.D., Professor of Physiology in ${ }^{3}$, Group Leader of Institute for Bioengineering of Catalonia (IBEC), Academic Director of Degree in Biomedical Engineering from University of Barcelona and member of ${ }^{7}$. JA: Ph.D. in Biophysics, Professor in University of Barcelona. MMM: Ph.D., M.D. Pneumologist in University Hospital of Bellvitge, Group Leader from interstitial lung disease in ${ }^{1}$, Coordinator of ${ }^{2}$ and Coordinator of the Corporative Program of investigation in Pulmonary fibrosis from ${ }^{7}$.

\section{Acknowledgements}

The authors thank Professor, M.D. Moisés Selman from the Instituto Nacional de Enfermedades Respiratorias (INER, Tlalpan, México) for his helpful comments and review of this manuscript. The authors also thank the members of the Technological and Scientific Centers of the University of Barcelona (Bellvitge, Barcelona, Spain) for their technical assistance and Roland Galgoczy from the Unit of Biophysics and Bioengineering (University of Barcelona, Spain) for his imaging assistance. Supported by FIS PI12/02455 (ISCIII, Instituto de Salud Carlos III), SOCAP (Societat Catalana de Pneumologia), FUCAP (Fundació Catalana de Pneumologia) and SEPAR (Sociedad Española de Neumología).

\section{Author details}

${ }^{1}$ Department of Pneumology, Unit of Interstitial Lung Diseases, University Hospital of Bellvitge, Barcelona, Spain. ${ }^{2}$ Pneumology Research Group, IDIBELL, University of Barcelona, Barcelona, Spain. ${ }^{3}$ Unit of Biophysics and Bioengineering, University of Barcelona, Barcelona, Spain. ${ }^{4}$ Department of Preventive Medicine, University Hospital of Bellvitge, Barcelona, Spain. ${ }^{5}$ Department of Pathology, University Hospital of Bellvitge, Barcelona, Spain. ${ }^{6}$ Department of Thoracic Surgery, University Hospital of Bellvitge, Barcelona, Spain. ${ }^{7}$ Research Network in Respiratory Diseases (Centro de Investigación Biomédica en Red (CIBER) de Enfermedades Respiratorias), ISCIII, Barcelona, Spain. ${ }^{8}$ Department of Biochemistry, University of Geneva, Science II, Geneva, Switzerland.

\section{Received: 22 May 2015 Accepted: 10 June 2015}

\section{Published online: 01 July 2015}

\section{References}

1. Clarke DL, Carruthers AM, Mustelin T, Murray LA. Matrix regulation of idiopathic pulmonary fibrosis: the role of enzymes. Fibrogenesis Tissue Repair. 2013;6:20

2. Cox TR, Erler JT. Remodeling and homeostasis of the extracellular matrix: implications for fibrotic diseases and cancer. Dis Model Mech. 2011;4:165-78.

3. Paszek MJ, Weaver VM. The tension mounts: mechanics meets morphogenesis and malignancy. J Mammary Gland Biol Neoplasia. 2004:9:325-42.

4. Liu M, Tanswell K, Post M. Mechanical force-induced signal transduction in lung cells. Am J Physiol Lung Cell Mol Physiol. 1999;277:667-83.

5. Butcher DT, Alliston T, Weaver VM. A tense situation: forcing tumor progression. Nat Rev Cancer. 2009;9:108-21.

6. Miron-Mendoza M, Seemann J, Grinnell F. Collagen fibril flow and tissue translocation coupled to fibroblast migration in $3 \mathrm{D}$ collagen matrices. Mol Biol Cell. 2008;19:2051-8.

7. Grinell F. Fibroblasts biology in three-dimensional collagen matrices. Trends Cell Boil. 2003;13:264-9.

8. Paszek MJ, Zahir N, Johnson KR, Lakins JN, Rozenberg Gl, Gefen A, et al. Tensional Homeostasis and the malignant phenotype. Cancer Cell. 2005;8:241-54

9. Raghu G, Collard HR, Egan JJ, Martinez FJ, Behr J, Brown KK, et al. An official ATS/ERS/JRS/ALAT statement. Idiopathic pulmonary fibrosis: evidence-based guidelines for diagnosis and management. Am J Respir Crit Care Med. 2011;183:788-824.

10. American Thoracic Society/European Respiratory Society International Multidisciplinary Consensus Classification of the Idiopathic Interstitial Pneumonias. Am J Respir Crit Care Med. 2002, 165:277-304

11. King TE, Pardo A, Selman M. Idiopathic Pulmonary fibrosis. Lancet. 2011;378:1949-61.

12. Nicholson AG, Fulford LG, Colby TV, du Bois RM, Hansell DM, Wells AU. The relationship between individual histologic features and disease progression in idiopathic pulmonary fibrosis. Am J Respir Crit Care Med. 2002;166:173-7.

13. Liu F, Mih JD, Shea BS, Kho AT, Sharif AS, Tager AM. DJ Tschumperlin: Feedback amplification of fibrosis through matrix stiffening and COX-2 suppression. J Cell Biol. 2010;190:693-706.

14. Booth AJ, Hadley R, Conrett AM, Dreffs AA, Matthes SA, Tsui LJ, et al. Acellular normal and fibrotic human lung matrices as a culture system for in vitro investigation. Am J Respir Crit Care Med. 2012;186:866-76.

15. Bell $\mathrm{E}$, Ivarsson B, Merrill C. Production of a tissue-like structure by contraction of collagen lattices by human fibroblasts of different proliferative potential in vitro. Proc Natl Acad Sci U S A. 1979:76:1274-8.

16. Johnson KR, Leight $J$, Weaver VM. Demystifying the effects of a threedimensional microenvironment in tissue morphogenesis. Methods Cell Biol. 2007;83:547-83.

17. Howard EW, Benton R, Ahern-Moore J, Tomasek JJ. Cellular contraction of collagen lattices is inhibited by nonenzymatic glycation. Exp Cell Res. 1996;228:132-7.

18. Yuen A, Laschinger C, Talior I, Lee W, Chan M, Birek J, et al. Methylglyoxalmodified collagen promotes myofibroblast differentiation. Matrix Biol. 2010;29:537-48.

19. Roy R, Boskey AL, Bonassar LJ. Non-enzymatic glycation of chondrocyteseeded collagen gels for cartilage tissue engineering. J Orthop Res. 2008;26:1434-9.

20. Roy R, Boskey A, Bonassar LJ. Processing of type I collagen gels using nonenzymatic glycation. J Biomed Mater Res. 2010;93:843-51.

21. Girton TS, Oegema TR, Tranquillo RT. Exploiting glycation to stiffen and strengthen tissue equivalents for tissue engineering. J Biomed Mater Res. 1999:46:87-92

22. Reddy GK. Cross-linking in collagen by nonenzymatic glycation increases the matrix stiffness in rabbit Achilles tendon. Exp Diabesity Res. 2004;5:143-53.

23. Baynes JW. The role of AGEs in aging: causation or correlation. Exp Gerontol. 2001;36:1527-37.

24. Avery NC, Bailey AJ. The effects of the Maillard reaction on the physical properties and cell interactions with collagen. Pathologie Biologie. 2006;54:387-95.

25. Semba RD, Nicklett EJ, Ferrucci L. Does accumulation of advanced glycation end products contribute to the aging phenotype? J Gerontol A Biol Sci Med Sci. 2010;65:963-75.

26. Schnider SL, Kohn RR. Effects of age and diabetes mellitus on the solubility and nonenzymatic glucosilation of human skin collagen. J Clin Invest. 1981;67:1630-5.

27. Francis-Sedlak ME, Uriel S, Larson JC, Greisler HP, Venerus DC, Brey EM. Characterization of type I collagen gels modified by glycation. Biomaterials. 2009;30:1851-6.

28. Cerami C, Founds H, Nicholl I, Mitsuhashi T, Giordano D, Vanpatten S, et al. Tobaco smoke is a source of toxic reactive glycation products. Proc Natl Acad Sci U S A. 1997;94:13915-20

29. Friedl P, Maaser K, Klein CE, Niggemann B, Krohne G, Zänker KS. Migration of highly aggressive MV3 melanoma cells in 3-dimensional collagen lattices results in local matrix reorganization and shedding of alpha2 and beta1 integrins and CD44. Cancer Res. 1997:57:2061-70.

30. Abramoff MD, Magelhaes PJ, Ram SJ. Image processing with ImageJ. Biophotonics Int. 2004;11:36-42

31. Monnier VM, Kohn RR, Cerami A. Accelerated age-related browning of human collagen in diabetes mellitus. Proc Natl Acad Sci U S A. 1984;81:583-7.

32. Bellmunt MJ, Portero M, Pamplona R, Cosso L, Odetti P, Prat J. Evidence for Maillard reaction in rat lung collagen and its relationship with solubility and age. Biochim Biophys Acta. 1995;1272:53-60

33. Alcaraz J, Xu R, Mori H, Nelson CM, Mroue R, Spencer VA, et al. Laminin and biomimetic extracellular elasticity enhance functional differentiation in mammary epithelia. EMBO J. 2008;27:2829-38.

34. Acerbi I, Luque T, Giménez A, Puig M, Reguart N, Farré R, et al. Integrinspecific mechanoresponses to compression and extension probed by cylindrical flat-ended AFM tips in lung cells. PLoS One. 2012;7:e32261. 
35. Alcaraz J, Buscemi L, Grabulosa M, Trepat X, Fabry B, Farré R, et al. Microrheology of human lung epithelial cells measured by atomic force microscopy. Biophys J. 2003;84:2071-9.

36. Uhal BD, Kim JK, Li X. Molina-Molina: Angiotensin-TGF-beta1 crosstalk in human idiopathic pulmonary fibrosis: autocrine mechanisms in myofibroblasts and macrophages. Curr Pharm Des. 2007;13:1247-56

37. Heidebrecht F, Schulz I, Keller M, Behrens SE, Bader A. Improved protocols for protein and RNA isolation from three-dimensional collagen sandwich cultures of primary hepatocytes. Anal Biochem. 2009;393:141-4.

38. Marinkovic A, Liu F, Tschumperlin DJ. Matrices of physiologic stiffness potently inactivate IPF fibroblasts. Am J Respir Cell Mol Biol. 2013;48:422-30.

39. Mih JD, Marinkovic A, Liu F, Sharif AS, Tschumperlin DJ. Matrix stiffness reverses the effect of actomyosin tension on cell proliferation. J Cell Science. 2012;125:5974-83.

40. Hadjipanayi E, Mudera V, Brown RA. Close dependence of fibroblast proliferation on collagen scaffold matrix stiffness. J Tissue Eng Regen Med. 2009:3:77-84.

41. Sung KE, Su G, Pehlke C, Trier SM, Eliceiri KW, Keely PJ, et al. Control of 3dimensional collagen matrix polymerization for reproducible human mammary fibroblast cell culture in microfluidic devices. Biomaterials. 2009:30:4833-41.

42. Suki B, Bates JHT. Extracellular matrix mechanics in lung parenchymal diseases. Respir Physiol Neurobiol. 2008;163:33-43.

43. Mason BN, Starchenko A, Williams RM, Bonassar LJ, Reinhart-King CA. Tuning three-dimensional collagen matrix stiffness independently of collagen concentration modulates endothelial cell behavior. Acta Biomater. 2013;9:4635-44

44. Arora PD, Narani N, McCulloch CA. The compliance of collagen gels regulates transforming growth factor- $\beta$ induction of $a$-smooth muscle actin in fibroblasts. Am J Pathol. 1999;154:871-82.

45. Hinz B, Celetta G, Tomasek JJ, Gabbiani G, Choponnier C. Alpha-smooth muscle actin expression upregulates fibroblast contractile activity. Mol Biol Cell. 2001;12:2730-41.

46. Steinberg BM, Smith K, Colozzo M, Pollack R. Establishment and transformation diminish the ability of fibroblasts to contract a native collagen gel. J Cell Biol. 1980:87:304-8.

\section{Submit your next manuscript to BioMed Central and take full advantage of:}

- Convenient online submission

- Thorough peer review

- No space constraints or color figure charges

- Immediate publication on acceptance

- Inclusion in PubMed, CAS, Scopus and Google Scholar

- Research which is freely available for redistribution 